\title{
Respiratory Outcomes of Patients With Amyotrophic Lateral Sclerosis: An Italian Nationwide Survey
}

\author{
Michele Vitacca MD and Andrea Vianello MD, on behalf of the Scientific Group on \\ Respiratory Intensive Care of the Italian Association of Hospital Pulmonologists
}

\begin{abstract}
BACKGROUND: Despite recommendations, respiratory therapies remain partially underutilized in patients with amyotrophic lateral sclerosis (ALS), and different practices are described in different countries. We surveyed attitudes and practice in Italy on ALS and other neuromuscular diseases (NMDs). METHODS: A questionnaire on ALS/NMD management was mailed to 178 pneumology units, which we classified into high-volume and low-volume centers according to the number of ALS/NMD patients followed in the last 5 years. RESULTS: Seventy-six pneumology units $(43 \%)$ responded, and the responding units had 1,772 ALS patients and 1,490 NMD patients. Difficulty clearing respiratory secretions and disturbed sleep were the main reasons the ALS patients were referred to pneumology units. Vital capacity (measured in the sitting position) and arterial blood gases were measured regularly, while respiratory muscle function and cough ability were routinely assessed in over $85 \%$ of the pneumology units (mainly in high-volume centers), and 94\% of pneumology units could provide noninvasive ventilation. Treatment of NMDs was similar to that of ALS, except for tracheostomy, which was less frequently performed in patients with NMDs. A multidisciplinary team approach to care was employed in approximately $90 \%$ of the responding pneumology units. Approximately a third of the units accessed palliative care services. CONCLUSIONS: Combined pulmonary function evaluation, long-term noninvasive ventilation, and assisted cough have become usual practices for ALS patients. Italian practices for ALS did not significantly differ from the approach to other NMDs. Key words: amyotrophic lateral sclerosis; respiratory failure; noninvasive ventilation. [Respir Care 2013;58(9):1433-1441. (C) 2013 Daedalus Enterprises]
\end{abstract}

\section{Introduction}

Amyotrophic lateral sclerosis (ALS), also called Lou Gehrig's disease, is an incurable and rapidly progressive

\footnotetext{
Dr Vitacca is affiliated with Divisione di Pneumologia Riabilitativa, Fondazione Salvatore Maugeri, Istituto di Ricovero e Cura a Carattere Scientifico Lumezzane, Brescia, Italy. Dr Vianello is affiliated with Fisiopatologia e Terapia Intensiva Respiratoria Ospedale, Università di Padova, Padova, Italy.
}

The authors have disclosed no conflicts of interest.

Correspondence: Michele Vitacca MD, Divisione di Pneumologia Riabilitativa, Fondazione Salvatore Maugeri, Istituto di Ricovero e Cura a Carattere Scientifico, Via Giuseppe Mazzini 129, 25066 Lumezzane, Brescia, Italy. E-mail: michele.vitacca@fsm.it.

DOI: $10.4187 /$ respcare.02236 neurodegenerative disease involving limbs and bulbar musculature. It is the most common form of motor neuron disease, affecting approximately 1.2-1.8/100,000 individuals. Clinically, ALS is characterized by progressive muscular weakness, leading to inability to move and speak in almost all patients. Death occurs 3-5 years after diagnosis. In the majority of the cases, intellect and awareness remain essentially unchanged, although mild to severe cognitive impairment has been reported in the literature. ${ }^{1,2}$

See the Related Editorial on Page 1555

Patients with ALS usually die from acute respiratory failure, due either to diaphragm weakness, ineffective cough, difficulty clearing respiratory secretions, and inability to handle oropharyngeal secretions, or to chronic progressive respiratory failure, which may be preceded by sleep- 
disordered breathing caused by nocturnal hypoventilation. ${ }^{3-5}$ Nevertheless, the treatment of respiratory complications in ALS patients was historically considered controversial, due to the lack of effective therapies and the fact that quality of life at an advanced stage was judged to be unduly compromised.

In addition, there is the consideration that the patient's dependence on home ventilatory support incurs a substantial physical and economic burden on family and caregivers. This has also raised the issue of the social ramifications of managing ALS individuals at a far advanced stage of the disease. ${ }^{6-8}$ However, in recent years, randomized controlled trials have indicated that long-term noninvasive ventilation (NIV) improves survival and quality of life. ${ }^{9-11}$ Patients with ALS have improved survival after tracheostomy for acute respiratory failure. ${ }^{12,13}$ As a result, a growing number of patients with ALS and severe ventilatory impairment are being successfully treated. In keeping with this changing approach, evidence-based practice guidelines recommend management of respiratory insufficiency with NIV as well as consideration of insufflation/ exsufflation to improve clearance of airway secretions, and tracheostomy to preserve quality of life in patients who accept long-term ventilator support. ${ }^{14,15}$ Despite these recommendations, respiratory therapies still remain partially underutilized in ALS patients, and marked variation has been reported in the use of ventilatory support within and between different countries, with important differences between referral centers. ${ }^{15-18}$ In this regard, NIV is underutilized in the United States, where only $21 \%$ of the 5,600 patients in the ALS Care Database study received NIV. ${ }^{15}$ We surveyed Italian pneumology units' diagnosis and management of ALS and other neuromuscular diseases (NMDs), for which the standard of care has been widely accepted for a longer period.

\section{Methods}

All pneumology units potentially involved in the respiratory care of patients with ALS and/or other NMDs were identified through the registry of the Italian Association of Hospital Pulmonologists. A questionnaire was developed by the co-authors in line with previous similar studies in Europe, ${ }^{19}$ and sent to the Italian Association of Hospital Pulmonologists Intensive Care and Rehabilitation Group physicians for comments and suggestions. The questionnaire was sent to all pneumology units in September 2011. The questionnaire was formally reviewed and approved by the local committee of the Foundation Salvatore Maugeri, Istituto di Ricovero e Cura a Carattere Scientifico Lumezzane, Brescia, Italy. The survey included 27 questions assessing the following aspects:

\section{QUICK LOOK}

\section{Current knowledge}

Respiratory therapy interventions in patients with amyotrophic lateral sclerosis (ALS) and other neuromuscular diseases can improve quality of life and longevity. The attitudes of caregivers can result in underutilization of interventions. The reasons for variable application of some interventions is unclear.

\section{What this paper contributes to our knowledge}

In Italy, combined pulmonary function evaluation, longterm noninvasive ventilation, and assisted cough techniques are the usual care for patients with ALS. The treatment strategy for ALS does not substantially differ from that for individuals with other neuromuscular disease, except for more frequent airway management.

- Characteristics of the pneumology unit: institution type, health resources, and number of patients followed over the past 5 years

- Clinical and pulmonary function data collected on the first respiratory visit: difficulty in clearing respiratory secretions was defined as the occurrence of frequent respiratory-tract infection, crisis of asphyxia, and/or "bubbly" breathing

- Parameters used as bad prognostic indicators

- Timing and modalities of follow-up

- Treatment strategies and multidisciplinary approach: physicians were invited to select an option only when routinely prescribed

- Caregiver identification and education

- Use of palliative/end-of-life care plans

Different types of questions were asked, including dichotomous yes/no questions, simple, and multiple-choice questions. The questionnaire was administered and completed on-line by connecting to a form on the Italian Association of Hospital Pulmonologists' Web site. Quantitative parameters are described as mean $\pm \mathrm{SD}$ or median and IQR, depending upon the normality of distribution. Qualitative parameters are described as number and percent.

A statistical analysis by one sample proportion test was performed to detect significant differences between management of ALS and NMDs and between centers with high and low expertise. Level of clinical expertise was defined by the number of patients with ALS and other NMDs cared for at the center over the past 5 years: for high expertise, at least 20 patients were required for each 
Table 1. Main Characteristics of the Pulmonary Units and Patients

\begin{tabular}{|c|c|}
\hline $\begin{array}{l}\text { Pulmonary units invited to } \\
\text { participate in the survey, no. }\end{array}$ & 178 \\
\hline $\begin{array}{l}\text { Pulmonary units that answered the } \\
\text { survey, no. }(\%)\end{array}$ & $76(42.7)$ \\
\hline \multicolumn{2}{|l|}{ Institution type, no. (\%) } \\
\hline University hospital & $6(7.9)$ \\
\hline Acute care non-university hospital & $61(80.3)$ \\
\hline Rehabilitation hospital & $9(11.8)$ \\
\hline Hospital beds per unit, mean \pm SD & $20 \pm 14$ \\
\hline \multicolumn{2}{|l|}{$\begin{array}{l}\text { Patients with neuromuscular disease/ } \\
\text { amyotrophic lateral sclerosis } \\
\text { under care during the last } \\
5 \mathrm{y}, \%\end{array}$} \\
\hline 0 & 1.9 \\
\hline $1-5$ & 11.1 \\
\hline$>5$ & 3.7 \\
\hline$>10$ & 29.6 \\
\hline$>20$ & 53.7 \\
\hline $\begin{array}{l}\text { Patients with amyotrophic lateral } \\
\text { sclerosis, no. }\end{array}$ & 1,772 \\
\hline $\begin{array}{l}\text { Duration of follow-up since } \\
\text { diagnosis, mean } \pm \text { SD months }\end{array}$ & $37 \pm 12$ \\
\hline $\begin{array}{l}\text { Patients with other neuromuscular } \\
\text { diseases, no. }\end{array}$ & 1,490 \\
\hline \multicolumn{2}{|l|}{ Type of neuromuscular disease, no. } \\
\hline Duchenne muscular dystrophy & 1,043 \\
\hline Type I spinal muscular atrophy & 45 \\
\hline $\begin{array}{l}\text { Limb girdle muscular disease } \\
2 \mathrm{C}, 2 \mathrm{D}, 2 \mathrm{~F}, 2 \mathrm{I}\end{array}$ & 25 \\
\hline Nemaline myopathy & 10 \\
\hline Acid maltase deficiency & 98 \\
\hline Congenital myasthenia & 65 \\
\hline Congenital myotonic dystrophy & 204 \\
\hline $\begin{array}{l}\text { Duration of follow-up since } \\
\text { diagnosis, mean } \pm \text { SD months }\end{array}$ & $108 \pm 24$ \\
\hline
\end{tabular}

disease category. Analysis was performed on the data submitted from the 74 pneumology units that completed the questionnaire. A 2 -sided $P$ value of $<.05$ was considered significant. Analyses were performed with statistics software (Stata 11.1, StataCorp, College Station, Texas).

\section{Results}

A total of 178 pneumology units were identified by the Italian Association of Hospital Pulmonologists' registry, and 76 units $(42.7 \%)$ answered the survey. Seventy-four questionnaires and 2 reply cards were completed. Table 1 describes the units that responded. The total numbers of patients with ALS and other NMDs under care during the last 5 years was 1,772 and 1,490, respectively.

Table 2 lists the symptoms resulting in the initial referral to a pneumology unit, pulmonary function tests performed at the initial evaluation, and parameters used as prognostic indicators. Difficulty in clearing respiratory secretions was observed far more frequently in patients with ALS than in patients with other NMDs. Dyspnea on exertion was common both in patients with ALS and in patients with other NMDs. Cognitive impairment, irritability, nocturnal awakenings, excessive daytime sleepiness, difficulty in concentrating, and disturbed sleep were more common in patients with NMDs. The proportion of responding pneumology units that reported that they assess respiratory function at the first referral was near $100 \%$, whereas slow sitting vital capacity (VC) and arterial blood gases (ABGs) were routinely measured, and nocturnal oximetry, maximum inspiratory pressure (MIP), maximum expiratory pressure (MEP), and maximum sniff nasal pressure were less frequently evaluated. Abnormalities of $\mathrm{P}_{\mathrm{aO}}$ and $\mathrm{P}_{\mathrm{aCO}_{2}}$, use of mechanical ventilation for $>18 \mathrm{~h} / \mathrm{d}$, and physician indication for tracheostomy ventilation were considered bad prognostic indicators.

Serial measurements of $\mathrm{VC}$ and ABGs were regularly performed during the follow-up period in the majority of the pneumology units (Figure). Nocturnal oximetry, cardiorespiratory monitoring, and polysomnography were considered necessary only if the patient was symptomatic. Overall, $70 \%$ of pneumology units used nocturnal respiratory studies to assess sleep-disordered breathing during follow-up. Frequency of follow-up visits was individualized in most centers, according to disease stage and the patient's need. A lower proportion of centers assessed respiratory status at a fixed time interval (every 3 or 6 months). In $13.2 \%$ of cases, a follow-up visit was not scheduled. The modalities of follow-up included: dedicated out-patient office (65.4\% of centers), hospital admission for the patient's special needs, including prescription of new devices, education reinforcement, and resetting of the ventilator $(51.9 \%)$; home visits $(28.8 \%)$; and a structured program of telesurveillance $(11.5 \%)$. When compared to patients with NMDs, VC and MIP/MEP measurement at the initial visit were more frequently evaluated in ALS individuals $(P=.03$ and $P<.001$, respectively). During the follow-up period, ABGs were more frequently measured in ALS patients ( $P=.006)$ (see the Figure).

Data on therapeutic interventions and parameters used as indicators to start NIV or initiate tracheostomy ventilation and the respiratory care setting for the management of exacerbations are reported in Table 3. Only $6 \%$ of the responding pneumology units indicated that they had no access to NIV treatment, and $12 \%$ did not routinely administer manual or mechanical cough assistance. Daytime hypercapnia, sleep-related hypoxemia, and a VC of $<50 \%$ of predicted were the parameters most commonly followed to initiate NIV. The symptoms most likely to trigger NIV prescription were dyspnea on exertion, fatigue, and orthopnea. Both patients with ALS and patients with other NMDs were considered eligible for tracheostomy when they could not be completely weaned from intubation, the 


\section{Respiratory Outcomes of Patients With Amyotrophic Lateral Sclerosis}

Table 2. Clinical Presentation, Pulmonary Function Tests Performed at Initial Evaluation, and Parameters Used as Bad Prognostic Indicators*

\begin{tabular}{|c|c|c|c|}
\hline & \multicolumn{2}{|c|}{ Percentage } & \multirow{2}{*}{$P$} \\
\hline & ALS & NMD & \\
\hline \multicolumn{4}{|l|}{ Symptoms resulting in the initial referral to pulmonary unit } \\
\hline Difficulty clearing respiratory secretions & 77.4 & 6 & $<.001$ \\
\hline Dyspnea on exertion & 77.4 & 68.9 & .11 \\
\hline Disturbed sleep & 58.5 & 83.6 & $<.001$ \\
\hline Extreme fatigue & 52.8 & 59 & .28 \\
\hline Nocturnal awakenings & 13.2 & 32.8 & $<.001$ \\
\hline Irritability & 9.4 & 19.7 & .03 \\
\hline Excessive daytime sleepiness & 9.4 & 19.7 & .03 \\
\hline Difficulty in concentrating & 9.4 & 21.3 & .01 \\
\hline Impaired cognition & 1.8 & 24.6 & .002 \\
\hline \multicolumn{4}{|l|}{ Pulmonary function test performed at the initial evaluation } \\
\hline Vital capacity sitting & 98.1 & 91.9 & .05 \\
\hline Blood gas analysis & 98.1 & 95.2 & .24 \\
\hline Nocturnal oximetry & 88.7 & 83.9 & .26 \\
\hline Maximum inspiratory/expiratory pressure & 86.8 & 79 & .10 \\
\hline Cardiorespiratory monitoring/polysomnography & 64.2 & 74.2 & .04 \\
\hline Peak cough flow & 56.6 & 58.1 & .79 \\
\hline Total lung capacity and inspiratory capacity & 54.7 & 54.8 & .98 \\
\hline Vital capacity lying & 47.2 & 56.5 & .10 \\
\hline Sniff inspiratory pressure & 15.1 & 17.7 & .55 \\
\hline \multicolumn{4}{|l|}{ Parameters used as bad prognostic indicators } \\
\hline Indication for tracheotomy & 64 & 53 & .058 \\
\hline Blood gas abnormalities & 51 & 40 & .053 \\
\hline Need for noninvasive ventilation & 42 & 43 & .86 \\
\hline Use of mechanical ventilation $>18 \mathrm{~h} / \mathrm{d}$ & 35 & 45 & .08 \\
\hline Swallowing ability & 28 & 32 & .46 \\
\hline Vital capacity $($ seated $)<50 \%$ & 27 & 22 & .30 \\
\hline Nighttime $\mathrm{S}_{\mathrm{pO}_{2}}<90 \%$ for $>30 \%$ of the recorded time & 25 & 20 & .28 \\
\hline Loss of vital capacity from sitting $>25 \%$ & 21 & 22 & .84 \\
\hline Peak cough flow $<180 \mathrm{~L} / \mathrm{min}$ & 21 & 22 & .84 \\
\hline Maximum inspiratory or expiratory pressure $<60 \%$ of predicted & 20 & 22 & .68 \\
\hline Pneumonia/atelectasis episodes & 17 & 16 & .81 \\
\hline Need for cough assistance & 16 & 15 & .81 \\
\hline Exacerbations with need for antibiotics & 9 & 7 & .50 \\
\hline Apnea-hypopnea index $>15$ events/h & 9 & 4 & .03 \\
\hline Speech ability & 8 & 8 & .99 \\
\hline $\begin{array}{l}\text { * Data from } 74 \text { pulmonary units that completed the questionnaire. } \\
\text { ALS }=\text { amyotrophic lateral sclerosis } \\
\text { NMD = neuromuscular disease other than ALS }\end{array}$ & & & \\
\hline
\end{tabular}

need for NIV was $>18 \mathrm{~h} / \mathrm{d}$, or they had severe swallowing impairment. Only $9.6 \%$ of responding pneumology units had never initiated tracheostomy ventilation in their patients. Acute respiratory problems were more frequently managed in a specialized respiratory ICU. However, a substantial proportion of ALS patients were treated during respiratory exacerbation in medical units not equipped with NIV.

A multidisciplinary team approach to care of patients with ALS was employed in approximately $90 \%$ of pneumology units, based on close cooperation between pulmo- nologists and neurologists (88.5\%), physiatrists $(57.7 \%)$, psychologists $(38.5 \%)$, and physiotherapists (76.9\%). Notably, collaboration with neurologists was defined as excellent or good in $51.9 \%$ of cases, to such an extent that $48.6 \%$ of pulmonologists had developed an integrated care protocol. Also, communication between neurologists and pulmonologists was significantly less satisfying in the low-referring centers. Family caregivers were identified by $100 \%$ of pneumology units when starting a patient on home mechanical ventilation. In addition, the total number of responding pneumology units regularly provided a 

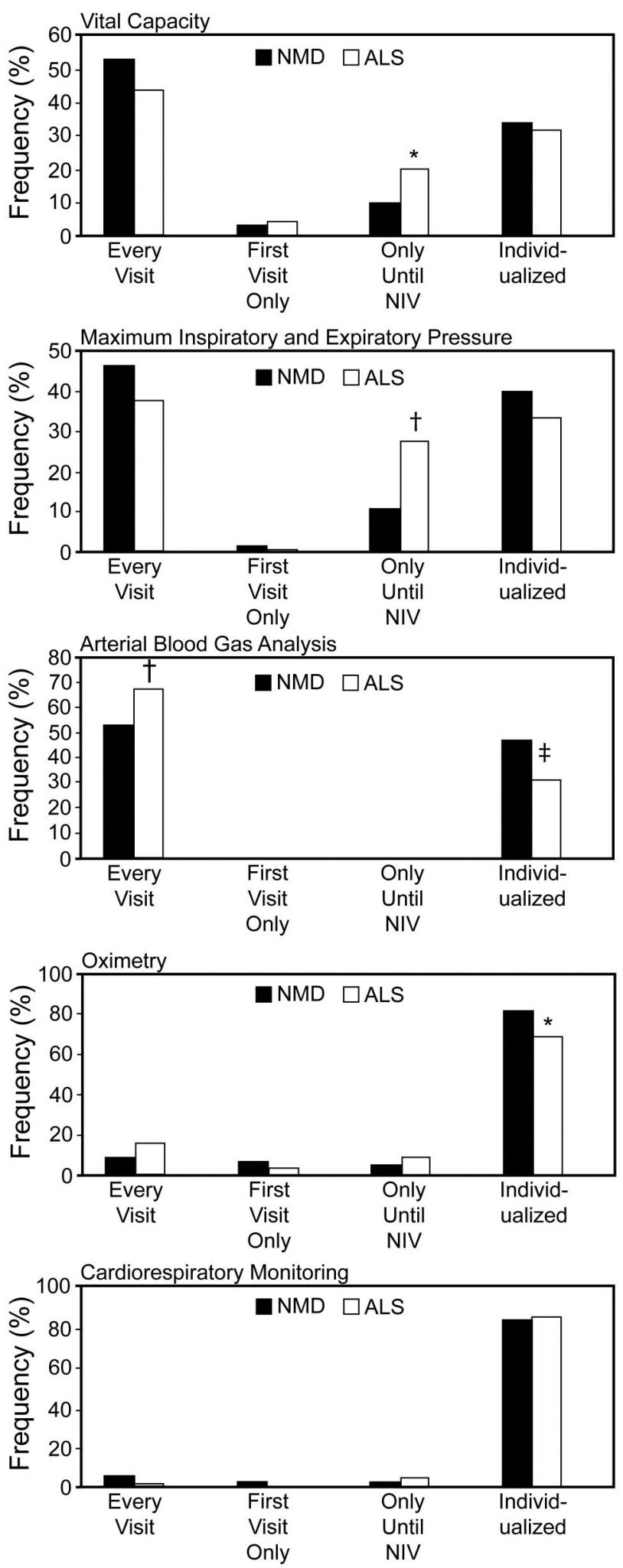

Figure. Frequency of pulmonary function testing during follow-up period in patients with amyotrophic lateral sclerosis versus other neuromuscular disease (NMD), in Italian pneumology units. ${ }^{*} P=.03 . \dagger P<.001 . \ddagger P=.006$. structured training program, including family and caregiver education. Only $34.6 \%$ of the pneumology units accessed palliative care services at the end of the life of the ALS patient, and a similar proportion $(28.1 \%)$ referred the NMD patient. Advance directive, concerning in which circumstances the patients would desire withdrawal from mechanical ventilation, were adopted in $32.1 \%$ and $29.4 \%$ of pneumology units, respectively, for patients with ALS and NMD.

Significant differences in care practice between high and low referring centers are reported in Table 4. High referring centers assessed respiratory muscle function and cough ability more accurately and were more likely to consider intervention with NIV when respiratory muscles strength was reduced. In addition, the specialized respiratory ICUs were more commonly trained and equipped to treat patients during exacerbation. High referring centers also offered structured follow-up programs, reported better collaboration between pulmonologists and neurologists, and more frequently used palliative measures at the final stages of the disease. In contrast, low referring centers had higher tracheostomy rates for patients with ALS who were difficult to wean from intubation.

\section{Discussion}

In recent years the approach to the care of patients with ALS who have developed respiratory failure has been clearly modified, and the treatment of respiratory complications has been encouraged, due to the development of new instruments such as NIV and cough assistance. ${ }^{20,21}$ However, despite these changes in clinical practice, management of ALS-related respiratory complications still remains a subject of ethical controversy.

We performed the first Italian national survey of respiratory care in individuals with ALS, which provided information on 76 pneumology units following 1,772 patients. It should be noted that replies were received from only $42.7 \%$ of the pneumology units, and we have no information on the number of patients managed by the non-responders. However, this number is likely to be small, since all major Italian ALS reference centers answered our questionnaire. Thus, we believe that our data may represent a comprehensive review of diagnostic and therapeutic patterns in Italy. On the other hand, this low response rate underlines the importance of disseminating critical guidelines and of ensuring appropriate management of ALS patients in those smaller centers that are likely to be less familiar with current recommendations.

The pneumology units routinely cared for ALS patients, for whom the initial referral was usually due to difficulty clearing respiratory secretions because of the inability to effectively cough or swallow. Clearing airway secretions is often a major problem for ALS patients, exacerbated by 


\section{Respiratory Outcomes of Patients With Amyotrophic Lateral Sclerosis}

Table 3. Treatment Options, Parameters Used as Indicators to Start Noninvasive Ventilation, Provision of Tracheostomy, and Setting for the Management of Exacerbation

\begin{tabular}{|c|c|c|c|}
\hline & \multicolumn{2}{|c|}{ Percentage } & \multirow{2}{*}{$P$} \\
\hline & ALS & NMD & \\
\hline \multicolumn{4}{|l|}{ Therapies } \\
\hline Long-term NIV & 94.2 & 96.5 & .28 \\
\hline Manual and/or mechanical cough assistance & 88.5 & 84.2 & .31 \\
\hline Artificial nutrition & 73.1 & 68.4 & .38 \\
\hline Ventilatory muscles training & 26.9 & 36.6 & .08 \\
\hline Physical therapy & 13.5 & 28.1 & $<.001$ \\
\hline Palliative drugs & 0 & 1.8 & .24 \\
\hline \multicolumn{4}{|l|}{ Indicators to start NIV } \\
\hline $\mathrm{P}_{\mathrm{aCO}_{2}}>45 \mathrm{~mm} \mathrm{Hg}$ & 88.5 & 93 & .13 \\
\hline Sleep-related hypoxemia & 84.6 & 94.7 & $<.001$ \\
\hline Sitting vital capacity $<50 \%$ & 67.3 & 64.9 & .67 \\
\hline Symptoms (dyspnea on exertion, orthopnea) & 61.5 & 52.6 & .13 \\
\hline Maximum inspiratory or expiratory pressure $<60 \%$ of predicted & 53.8 & 47.4 & .27 \\
\hline \multicolumn{4}{|l|}{ Mechanical ventilation via tracheostomy } \\
\hline Inability to be weaned from intubation & 82.7 & 80.7 & .66 \\
\hline Need for NIV $>18 \mathrm{~h} / \mathrm{d}$, also without bulbar impairment & 67.3 & 50.9 & .002 \\
\hline Severe swallowing disturbances & 32.7 & 26.3 & .23 \\
\hline Never provided & 9.6 & 17.5 & .07 \\
\hline \multicolumn{4}{|l|}{ Acute respiratory care setting } \\
\hline Specialized respiratory ICU & 50 & 59 & .12 \\
\hline Medical unit equipped with NIV & 32 & 25.3 & .18 \\
\hline Medical unit not equipped with NIV & 16 & 14 & .62 \\
\hline Home & 2 & 1.7 & .84 \\
\hline \multicolumn{4}{|l|}{$\begin{array}{l}\text { ALS }=\text { amyotrophic lateral sclerosis } \\
\text { NMD = neuromuscular disease other than ALS } \\
\text { NIV = noninvasive ventilation }\end{array}$} \\
\hline
\end{tabular}

Table 4. Differences in Practice Between High and Low Referring Centers That Completed the Questionnaire

\begin{tabular}{|c|c|c|c|}
\hline & \multicolumn{2}{|c|}{ Percentage } & \multirow[b]{2}{*}{$P$} \\
\hline & $\begin{array}{c}\text { High } \\
\text { Referring Centers } \\
(n=41)\end{array}$ & $\begin{array}{c}\text { Low } \\
\text { Referring Centers } \\
(n=33)\end{array}$ & \\
\hline \multicolumn{4}{|l|}{ Pulmonary function tests performed at the initial evaluation } \\
\hline Maximum inspiratory/expiratory pressure & 93 & 55 & .03 \\
\hline Peak cough flow & 87 & 40 & .03 \\
\hline \multicolumn{4}{|l|}{ Indicators to start noninvasive ventilation } \\
\hline Maximum inspiratory or expiratory pressure $<60 \%$ of predicted & 70 & 45 & .04 \\
\hline \multicolumn{4}{|l|}{ Mechanical ventilation via tracheostomy } \\
\hline Inability to be weaned from intubation & 45 & 70 & .04 \\
\hline \multicolumn{4}{|l|}{ Acute respiratory care setting } \\
\hline Specialized respiratory ICU & 78 & 45 & .03 \\
\hline Provision of a follow-up visit schedule & 75 & 40 & .03 \\
\hline Adoption of a protocol for advance directives & 70 & 25 & .03 \\
\hline Excellent or good collaboration with neurologists & 45 & 23 & .04 \\
\hline
\end{tabular}

the inability to swallow saliva or food without aspiration, and was a frequent reason why physicians began tracheostomy ventilation.
Less than $60 \%$ of Italian pneumology units reported regular measurement of peak cough flow, which is a reliable parameter of cough ability and allows simple assess- 
ment and monitoring of its evolution. ${ }^{22}$ Low referring centers were less familiar with the use of peak cough flow guidelines. Another symptom of respiratory compromise is progressive $\mathrm{CO}_{2}$ retention. This can be subtle, and represents an underestimated manifestation of respiratory impairment. ${ }^{23-25}$ Pulmonary function testing at the initial visit routinely included sitting VC, MIP, MEP, maximum sniff nasal pressure, and daytime ABGs. The combination of respiratory muscle strength and pulmonary function measures for detection of early respiratory involvement in ALS patients can be more effective than reliance on one particular test. ${ }^{26,27}$ It is noteworthy that pulmonary function data on the first visit may have underestimated the frequency of subsequent measurements of MIP/MEP. If centers would perform these tests when baseline FVC becomes abnormal, this would avoid unnecessary testing in patients with a normal FVC.

Nocturnal oximetry was performed in about $90 \%$ of pneumology units during the initial evaluation, based on the knowledge that alveolar hypoventilation may occur during the hours of sleep, before daytime symptoms become apparent. Thus, sleep hypoxemia may be one of the earliest indicators of respiratory insufficiency in ALS individuals. ${ }^{28}$ It is noteworthy that recent guidelines have concluded that nocturnal oximetry alone is an acceptable method of screening for hypoventilation in asymptomatic individuals with NMD, assuming that clinically important hypoventilation of neuromuscular origin is unlikely to occur in the absence of desaturation below 93\%. ${ }^{29}$ Following initial nocturnal oxygen saturation assessment, most pneumology units performed a new assessment of sleep-related hypoventilation only if the onset of sleep was associated with symptoms, consistent with previous clinical practice recommendations. ${ }^{16}$

In comparison with the first visit of patients suffering from NMDs other than ALS, our data indicate that the inability to cough was less frequent and that respiratory muscle function was likely to be less accurately assessed than in individuals with ALS. According to current guidelines the management of respiratory insufficiency in ALS patients should include the administration of NIV as a primary treatment modality, based on the evidence of improved survival, quality of life, symptoms, and health economic evaluation. ${ }^{11,30}$ For this reason, criteria have been proposed as indication for starting ventilatory treatment. ${ }^{14,31}$ In regard to use of assisted ventilation, the main finding of our survey is that domiciliary NIV is currently prescribed by nearly all the pneumology units surveyed, and that criteria commonly followed in the decision to initiate longterm NIV are: daytime hypercapnia (in $89 \%$ of units), sleep-related hypoxemia (in $85 \%$ of units), and sitting VC below 50\% (in 67\% of units). Although these criteria are in keeping with current consensus recommendations,
NIV should be considered at the earliest sign of nocturnal hypoventilation or respiratory insufficiency. ${ }^{14}$

It is noteworthy, however, that more than one third of the centers considered patients' symptoms as of secondary importance for indicators in starting NIV. This attitude is different from that of United Kingdom and Canadian physicians, asserting that patient symptoms are of primary importance for initiating NIV. Unless patients are motivated by the desire for symptom relief, they are unlikely to adhere to NIV.17,18,32

The transition to tracheostomy ventilation in ALS patients, when bulbar impairment becomes severe, varies widely in countries, from 1.4-15\% of referring centers in the United States, to the majority of ALS patients in Japan. ${ }^{33,34}$ Our results indicate that only $10 \%$ of Italian pulmonologists intentionally decide not to initiate tracheostomy ventilation in ALS patients, and 17\% in NMD patients. The Italian pulmonologists recommend tracheostomy ventilation if one of the following conditions is present: patient intubated and unweanable from invasive mechanical ventilation; patient using NIV for $>18 \mathrm{~h} / \mathrm{d}$, even without severe bulbar impairment; poor NIV tolerance; or severe bulbar symptoms. Factors promoting the use of tracheostomy ventilation include a late diagnosis of respiratory complications, suboptimal follow-up, and views on withholding ventilatory support. The use of the "do-notintubate/do-not-resuscitate" code on individuals with endstage respiratory disorders is less common among Italian pulmunologists, in comparison with other countries. ${ }^{35}$ Only $32.1 \%$ of pneumology units discussed end-of-life issues and obtained advance directives from their patients concerning life-support. This reveals that not enough effort is being made to educate ALS patients on breathing support options, if they desire to prolong their life and still continue to stay active socially.

The more common use of tracheostomy ventilation in Italy could reflect the greater availability of home care resources in Italy. In fact, respiratory home care is provided at no cost by the Italian national health system. ${ }^{36}$ Our findings suggest that in Italy the treatment approach is very similar in ALS and other NMDs. The only differences were that sleep-hypoxemia was considered a stronger indication for NIV in NMDs, and tracheostomy ventilation was more commonly used in ALS than other NMDs. Limiting the use of tracheostomy ventilation in patients with a not rapidly progressive NMD is in accordance with expert opinion that tracheostomy is needed only in individuals with severe loss of bulbar muscle control and inability to protect the airway from aspiration. ${ }^{37,38}$ Based on our data, in totally ventilator-dependent patients with preserved bulbar function, 24-hour NIV via mouthpiece is not considered a viable option, probably due to inadequate team experience. Our survey shows evidence of close cooperation among pulmonologists, neurologists, and physiatrists. 


\section{Respiratory Outcomes of Patients With Amyotrophic Lateral Sclerosis}

This is in line with studies indicating the importance of a multidisciplinary approach aimed at assisting ALS patients with care-options decision-making throughout the disease process. ${ }^{39,40}$

Finally, our survey suggests that ALS practice recommendations are more closely followed by highly specialized centers than by less experienced clinics. The high referral centers were more likely to accurately assess respiratory muscle function, both at the initial visit and during follow-up, with over $90 \%$ of clinics routinely measuring MIP, MEP, and peak cough flow, and providing optimal ventilatory management. This includes limiting the use of tracheostomy ventilation and following advance directives. Discrepancy in the approach to monitoring and managing pulmonary function between high and low volume referral centers has also been reported by other authors, concluding that NIV represents an increasingly utilized option and improves survival among patients followed by dedicated, highly experienced, tertiary ALS centers. ${ }^{41}$

\section{Limitations}

There is a lack of information on excessive oral secretions or saliva as an airway problem, and on the use of oropharyngeal suctioning for upper airway/oral secretions. This may have limited the ability to differentiate between bronchial and oral secretions, considering that the respondents may not have identified this difference, and that oral secretions continue to increase in bulbar patients and are ultimately a key problem in tolerating NIV.

Survival time was not determined. Survival may be an indicator of optimal NIV use and level of respiratory care. However, evaluating survival was not included in the purpose of our survey, which was essentially dedicated to organizational interventions

The definition of high clinical expertise as at least 20 patients cared for over the past 5 years was arbitrary, although related to the average number of patients followed by all pneumology units.

\section{Conclusions}

Combined pulmonary function evaluation, long-term NIV, and assisted coughing techniques have become the usual care for ALS individuals in Italy. In addition, tracheostomy ventilation, following a respiratory crisis, is regarded as a viable option in most cases, suggesting a high rate of complications and/or failed use of NIV. Moreover, provision of information on respiratory complications and end-of-life decisions is still insufficient and needs to be improved, so patients and caregivers can be more active participants in disease management. The treatment strategy for ALS did not significantly differ from that for other NMDs, except for more frequent airway manage- ment. Finally, further investigation on reasons for emergency hospitalizations and unplanned tracheostomy are warranted.

\section{ACKNOWLEDGMENTS}

We thank Dr Alessandro Bettini for editing assistance, and Dr Mara Paneroni for statistical assistance.

\section{REFERENCES}

1. Strong M, Rosenfeld J. Amyotrophic lateral sclerosis: a review of current concepts. Amyotroph Lateral Scler Other Motor Neuron Disord 2003;4(3):136-143.

2. Raaphorst J, de Visser M, Linssen WH, de Haan RJ, Schmand B. The cognitive profile of amyotrophic lateral sclerosis: a. metaanalysis. Amyotroph Lateral Scler 2010;11(1-2):27-37.

3. Hadjikoutis S, Wiles CM. Respiratory complications related to bulbar dysfunction in motor neurone disease. Acta Neurol Scand 2001; 103(4):207-2013.

4. Mustfa N, Moxham J. Respiratory muscle assessment in motor neurone disease. QJ Med 2001;94(9):497-502.

5. Bach JR. Amyotrophic lateral sclerosis: prolongation of life by noninvasive respiratory aids. Chest 2002;122(1):92-98.

6. Moss AH, Oppenheimer EA, Casey P, Cazzolli PA, Roos RP, Stocking CB, Siegler M. Patients with amyotrophic lateral sclerosis receiving long-term mechanical ventilation: advance care planning and outcomes. Chest 1996;110(1):249-255.

7. Chiò A, Gauthier A, Calvo A, Ghiglione P, Mutani R. Caregiver burden and patients' perception of being a burden in ALS. Neurology 2005;64(10):1780-1782.

8. Van Den Berg JP, Buskens E, Lindeman E, Van Den Berg LH. The costs of amyotrophic lateral sclerosis, according to type of care. Amyotroph Lateral Scler 2009;10(1):27-34.

9. Lyall RA, Donaldson D, Fleming T, Wood C, Newsom-Davis I, Polkey MI, et al. A prospective study of quality of life in ALS patients treated with noninvasive ventilation. Neurology 2001;57(1): 153-156.

10. Bourke SC, Bullock RE, Williams TL, Shaw PJ, Gibson GJ. Noninvasive ventilation in ALS: indications and effect on quality of life. Neurology 2003;6(2):171-177.

11. Bourke SC, Tomlinson M, Williams TL, Bullock RE, Shaw PJ, Gibson GJ. Effects of non-invasive ventilation on survival and quality of life in patients with amyotrophic lateral sclerosis: a randomised controlled trial. Lancet Neurol 2006;5(2):140-147.

12. Lo Coco D, Marchese S, La Bella V, Piccoli T, Lo Coco A. The amyotrophic lateral sclerosis functional rating scale predicts survival time in amyotrophic lateral sclerosis patients on invasive mechanical ventilation. Chest 2007;132(1):64-69.

13. Vianello A, Arcaro G, Palmieri A, Ermani M, Braccioni F, Gallan F, et al. Survival and quality of life after tracheostomy for acute respiratory failure in patients with amyotrophic lateral sclerosis. J Crit Care. 2011;26(3):329.e7-e14.

14. Miller RG, Jackson CE, Kasarskis EJ, England JD, Forshew D, Johnston W, et al. Practice parameter update: the care of the patient with amyotrophic lateral sclerosis: drug, nutritional, and respiratory therapies (an evidence-based review): Report of the Quality Standards Subcommittee of the American Academy of Neurology. Neurology 2009;73(15):1218-1226.

15. McKim DA, Road J, Avendano M, Abdool S, Cote F, Duguid N, Fraser J, et al; Canadian Thoracic Society Home Mechanical Ventilation Committee. Home mechanical ventilation: a Canadian Thoracic Society clinical practice guideline. Can Respir J 2011;18(4): 197-215. 


\section{Respiratory Outcomes of Patients With Amyotrophic Lateral Sclerosis}

16. Melo J, Homma A, Iturriaga E, Frierson L, Amato A, Anzueto A, Jackson C. Pulmonary evaluation and prevalence of non-invasive ventilation in patients with amyotrophic lateral sclerosis: a multicenter survey and proposal of a pulmonary protocol. J Neurol Sci 1999;169(1-2):114-117.

17. Bourke SC, Williams TL, Bullock RE, Gibson GJ, Shaw PJ. Noninvasive ventilation in motor neuron disease: current UK practice. Amotroph Lateral Scler Other Motor Neuron Disord 2002;3(3): 145-149.

18. Ritsma BR, Berger MJ, Charland DA, Khoury MA, Phillips JT, Quon MJ, et al. NIPPV: prevalence, approach and barriers to use at Canadian ALS centers. Can J Neurol Sci 2010;37(1):54-60.

19. Lloyd-Owen SJ, Donaldson GC, Ambrosino N, Escarabill J, Farre R, Fauroux B, et al. Patterns of home mechanical ventilation use in Europe: results from the Eurovent survey. Eur Respir J 2005;25(6): 1025-1031.

20. Robbins RA, Simmons Z, Bremer BA, Walsh SM, Fischer S. Quality of life in ALS is maintained as physical function declines. Neurology 2001;56(4):442-444.

21. Kaub-Wittemer D, von Steinbuchel N, Wasner M, Laier-Groenveld G, Borasio GD. Quality of life and psychosocial issues in ventilated patients with amyotrophic lateral sclerosis and their caregivers. J Pain Symptom Manage 2003;26(4):890-896.

22. Suarez AA, Pessolano FA, Monteiro SG, Ferreyra G, Capria ME, Mesa L, et al. Peak flow and peak cough flow in the evaluation of expiratory muscle weakness and bulbar impairment in patients with neuromuscular diseases. Am J Phys Med Rehabil 2002;81(7): 506-511.

23. Chaudri MB, Liu C, Hubbard R, Jefferson D, Kinnear WJ. Relationship between supramaximal flow during cough and mortality in motor neurone disease. Eur Respir J 2002;19(3):434-438.

24. Sancho J, Servera E, Diaz J, Marin J. Predictors of ineffective cough during a chest infection in patients with stable amyotrophic lateral sclerosis. Am J Respir Crit Care Med 2007;175(12):1266-1271.

25. Hardiman O. Symptomatic treatment of respiratory and nutritional failure in amyotrophic lateral sclerosis. J Neurol 2000;247(4):245-251.

26. National Institute for Health and Clinical Excellence. Understanding NICE guidance: information for people who use NHS services. Noninvasive ventilation for people with motor neurone disease. London: (CG105) National Institute for Health and Clinical Excellence; 2010.

27. Lyall RA, Donaldson N, Polkey MI, Leigh PN, Moxham J. Respiratory muscle strength and ventilatory failure in amyotrophic lateral sclerosis. Brain 2001;124(Pt10):2000-2013.

28. Miller RG, Rosenberg JA, Gelinas DF, Mitsumoto H, Newman D, Sufit R, et al. Practice parameter: the care of the patient with amyotrophic lateral sclerosis (an evidence-based review): report of the Quality Standards Subcommittee of the American Academy of
Neurology: ALS Practice Parameters Task Force. Neurology 1999; 52(7):1311-1323.

29. Hull J, Aniapravan R, Chan E, Chatwin M, Forton J, Gallagher J, et al. British Thoracic Society guideline for respiratory management of children with neuromuscular weakness. Thorax 2012;67(Suppl 1): i1-i40.

30. Mustfa N, Walsh E, Bryant V, Lyall RA, Addington-Hall J, Goldstein LH, et al. The effect of noninvasive ventilation on ALS patients and their caregivers. Neurology 2006;66(8):1211-1217.

31. Clinical indications for noninvasive positive pressure ventilation in chronic respiratory failure due to restrictive lung disease, COPD, and nocturnal hypoventilation: a consensus conference report. Chest 1999; 116(2):521-534.

32. Perrin C, Unterborn JN, D'Ambrosio C, Hill NS. Pulmonary complications of chronic neuromuscular diseases and their management. Muscle Nerve 2004;29(1):5-27.

33. Moss AH, Casey P, Stocking CB, Roos RP, Brooks BR, Siegler M. Home ventilation for amyotrophic lateral sclerosis patients: outcomes, costs and patient, family, and physician attitudes. Neurology 1993; 43(2):438-443.

34. Borasio GD, Gelinas D, Yanagisawa N. Mechanical ventilation in amyotrophic lateral sclerosis: a cross-cultural perspective. J Neurol 1998;245(Suppl 2):S7-S12.

35. Nava S, Sturani C, Hartl S, Magni G, Ciontu M, Corrado A. Endof-life decision-making in respiratory intermediate care units: a European survey. Eur Respir J 2007;30(1):156-164.

36. Oppenheimer EA. Amyotrophic lateral sclerosis. Eur Respir Rev 1992;2:323-329.

37. Bach JR, Bianchi C, Finder J, Fragasso T, Goncalves MR, Ishikawa $\mathrm{Y}$, et al. Tracheostomy tubes are not needed for Duchenne muscular dystrophy. Eur Respir J 2007;30(1):179-180.

38. Cazzolli PA, Brooks BR, Lewarski JL, McKim DA, Chatburn RL. Oral Secretion Scale (OSS) score in amyotrophic lateral sclerosis patients is associated with tolerance of non-invasive positive pressure ventilation, need for hospice or transition to tracheal positive pressure ventilation (TPPV) and survival (abstract). Amyotroph Lat Scler 2010;11(Suppl 1):140.

39. Van den Berg JP, Kalmijn S, Lindeman E, Veldink JH, de Visser M, Van der Graaff MM, et al. Multidisciplinary ALS care improves quality of life in patients with ALS. Neurology 2005;65(8):1264-1267.

40. Andersen PM, Borasio GD, Dengler R, Hardiman O, Kollewe K, Leigh PN, et al. EFNS task force on management of amyotrophic lateral sclerosis: guidelines for diagnosing and clinical care of patients and relatives. Eur J Neurol 2005;12(12):921-938.

41. Chiò A, Calvo A, Moglia C, Gamna F, Mattei A, Mazzini L, Mora G. Non-invasive ventilation in amyotrophic lateral sclerosis: a 10 year population based study. J Neurol Neurosurg Psychiatry 2012;83(4):377-381.

This article is approved for Continuing Respiratory Care Education credit. For information and to obtain your CRCE

(free to AARC members) visit www.rcjournal.com

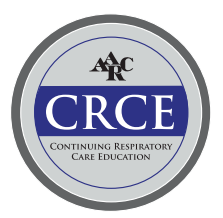

